\title{
SOBRE A SIGNIFICÂNCIA DO PASSADO PARA A AÇÃO PRESENTE E FUTURA
}

\author{
CHRISTIAN GUDEHUS \\ Ruhr-Universität-Bochum (RUB - Alemanha)
}

\section{RESUMO}

Recordação e memória são fenômenos secundários. Preenchem funções vitais para a ação humana individual e coletiva. Assim sendo, precisam ser investigados neste contexto, e não como um tema sui generis. Uma forma de dar concretude a esta afirmação é combinando esses dois fenômenos com teorias da ação encontradas nas ciências sociais e nas ciências cognitivas. As teorias da ação, de diversas origens, são modelos que buscam reconstruir o comportamento individual. Partilham o pressuposto de que os atores interpretam as situações nas quais se encontram e iniciam ações de acordo com suas interpretações. Esse processo aparentemente simples baseia-se em várias condições. As percepções supostamente individuais de tais situações já estão previamente moldadas pela cultura. Adicionalmente, existem modos e padrões de interpretação baseados em experiências ou repassados de uma geração a outra. Portanto, os atores podem basear-se em modelos de ação já disponíveis dos quais têm maior ou menor consciência e que tanto podem resultar de um processo de avaliação reflexiva quanto ser aplicados automaticamente. Circulam nas ciências sociais e cognitivas diversos conceitos que descrevem essas experiências sedimentadas. Este artigo propõe uma expansão consistente do conceito de recordação/memória para incluir conceitos diretamente resultantes do passado. Esses conceitos abrangem eventos, relacionamentos, dependências etc. que não necessariamente precisam continuar existindo até o presente específico do qual se esteja falando.

\begin{abstract}
Remembrance and memory are secondary phenomena. They fulfill vital functions for individual and collective human action. Accordingly, they must be investigated in this context rather than as a subject sui generis. One way to realize this claim is to combine them with social-scientific theories of action.

Theories of action of various proveniences are models that attempt to reconstruct individual behavior. Their commonly shared presumption is that actors interpret situations in which they find themselves and initiate actions in accordance with their readings. This seemingly simple process is based on various conditions: The allegedly individual perceptions of such situations already are culturally preformed. In addition, modes and patterns of interpretation exist that are based on experiences or passed on from one generation to the next. Therefore, actors can resort to ready-made models of action of which they are more or less aware and which can be either the outcome of a process of reflective evaluation or which are applied automatically. Several concepts describing such sedimented experiences are circulated in the social and cognitive sciences. This paper argues for a consistent expansion of the concept of remembrance/memory to include concepts that directly result from the past. These concepts comprise events, relationships, dependencies etc. that do not necessarily have to continue to exist up until the respective present being talked about.
\end{abstract}

KEYWORDS: memory; experiences; past; action.

PALAVRAS-CHAVE: memória; experiências; passado; ação. 


\section{O passado e o comportamento humano}

Que significância têm o passado e sua atualização, isto é, a recordação, para a ação humana? Quando se parte desta pergunta, a recordação e a memória já não são, em si mesmas, objetos de pesquisa: o que se estuda é o papel que desempenham na constituição do comportamento individual e coletivo, ou seja, são tomadas como fenômenos secundários. Para esse propósito, os conceitos teóricos que lidam com questões como o que é ação e o que a motiva devem estar relacionados com as hipóteses teóricas subjacentes relativas à memória. $\mathrm{O}$ elemento comum aqui é tempo, ou os três tempos: passado, presente e futuro. Pode-se ver que a história da computação do tempo exibe aquilo que, em essência, a torna possível, ou seja, a mudança ${ }^{1}$. Embora os fenômenos naturais, com os quais os calendários sempre estiveram alinhados, repitam-se em ritmos regulares, os seres vivos envelhecem fisicamente a partir da transformação de suas estruturas celulares. Além disso, resíduos ou traços de vários eventos também podem ser lidos naquilo que está aparente. Assim, por exemplo, os galhos atrofiados de uma árvore sugerem um período de fome ou seca, e as cicatrizes de um animal falam de uma luta. Mas esses resultados do passado não alteram apenas a casca ou a pele naquele ponto diretamente afetado. A árvore pode mudar o curso de seu desenvolvimento e talvez desenvolver novas raízes ou novos galhos. De fato, a Oenothera biennis, uma planta ornamental, pode mudar sua configuração genética em uma única geração em resposta à infestação de pragas ${ }^{2}$. Um elemento adicional entra em cena quando se trata de animais: a experiência. Como resultado (e isso, sem dúvida, está longe de se aplicar a todos os animais), eles se tornam mais cautelosos, mais hábeis e até mais capazes, conseguindo, assim, evitar danos futuros ${ }^{3}$. Em tais casos, isso significaria que 0 passado, transformado em experiência, poderia mudar o comportamento. No entanto, é evidente que a experiência é transmitida de diferentes formas. Não apenas programas genéticos e, portanto, a aparência, mas também comportamentos são consequências do passado, já que são preservados como mutações especialmente adaptadas a determinadas condições ambientais. Mamíferos altamente evoluídos, como a Ornicus orca, ou baleia assassina, efetivamente treinam seus descendentes e, assim, os preparam para o futuro ${ }^{4}$. As orcas são bastante flexíveis para adaptar seu próprio comportamento a

\footnotetext{
${ }^{1}$ VOGTHERR, Thomas. Zeitrechnung. Von den Sumerern bis zur Swatch. Munique: C.H.Beck, 2001.

${ }^{2}$ AGRAWAL, Anurag A. / Hastings, Amy P. / Johnson, Marc T. J. / Maron, John L. / Salminen, Juha-Pekka. Insect Herbivores Drive Real-Time Ecological and Evolutionary Change in Plant Populations. Science 5, v. 338, n. 6103, pp. 113-116, outubro de 2012 [DOI: 10.1126/science.1225977]

${ }^{3} \mathrm{Na}$ "Declaração de Consciência de Cambridge", um grupo de renomados neurocientistas argumenta que, a seu ver, os animais possuem uma consciência, e afirma: "Evidências convergentes indicam que animais não humanos têm os substratos neuroanatômicos, neuroquímicos e neurofisiológicos de estados de consciência e a capacidade de exibir comportamentos intencionais." (The Cambridge Declaration on Consciousness).

${ }^{4}$ GUINET, Christophe / Bouvier, Jérome. Development of intentional stranding hunting techniques in killer whale (Orcinus orca) calves at Crozet Archipelago. Canadian Journal of Zoology, 73(1): pp. 27-33, 10.1139/z95-004, 1995.
} 
situações cambiantes quando caçam e quando selecionam a presa. Além disso, dispõem de complexas estratégias de caça que, de um lado, baseiam-se na experiência e, de outro, requerem uma medida de planejamento que é notável para o mundo animal ${ }^{5}$. Em suma, o passado, particularmente sob a forma de experiência, é relevante para o comportamento - ou, mais exatamente, é constitutivo dos padrões de comportamento entre seres vivos não humanos.

Isso é ainda mais relevante quando se trata de seres humanos, já que podem armazenar e atualizar o passado de formas muito variadas. No entanto, o que significam realmente essas duas atividades e como se inter-relacionam permanece sendo a questão central de todas as pesquisas sobre memória e recordação. Se pesquisarmos o tema da significância do passado para a ação, já encontraremos em diversos autores clássicos uma versão muito mais ampla e abrangente do que se pode entender pelo termo recordação. A compreensão atual, que está associada, em particular, aos trabalhos do psicólogo social Frederic Bartlett ${ }^{6}$ e do sociólogo Maurice Halbwachs ${ }^{7}$, implica que a recordação, entendida como o resultado de lembrar, é, em múltiplos aspectos, um constructo social e, portanto, compatível com os conceitos da sociologia do conhecimento ${ }^{8}$. Matthias Berek, por exemplo, sugere precisamente tal leitura das chamadas culturas da recordação ${ }^{9}$. No entanto, em termos da história acadêmica, essa perspectiva deve parte de seu sucesso às chamadas teorias pós-modernas da história, como a de Hayden White ${ }^{10}$, na medida em que, também para elas, o caráter construcionista das narrativas do passado fornece uma base fundamental. Como quer que seja, as consequências do passado não são, essencialmente, o ponto de partida e têm, portanto, uma relevância apenas marginal para a ação como forma de atualizações da narrativa, sendo muito mais relevantes para uma explicação retrospectiva e significativa da ação. Entretanto, mesmo em textos como os de Bartlett poderiam ser encontradas indicações de outro tipo de traço do passado. Por exemplo, os ingleses adaptam uma história estrangeira (em termos dos nomes e das estruturas do enredo) de uma forma específica que resulta dos modos culturalmente transmitidos de percepção, interpretação e narração de que dispõem ${ }^{11}$. Mesmo que tudo isso já tenha sido discutido sob a rubrica de recordação social, a cultura é, não

\footnotetext{
${ }^{5}$ SMITH, Thomas G. / Siniff, Donald B. / Reichle, Richard / Stone, Sheridan. Coordinated behavior of killer whales, Orcinus orca, hunting a crabeater seal, Lobodon carcinophagus. Canadian Journal of Zoology, 59(6): pp. 1185-1189, 10.1139/z81-167, 1981.

6 BARTLETT, Frederic. Remembering. A Study in Experimental and Social Psychology. Cambridge: Cambridge University Press, 1932.

${ }^{7}$ HALBWACHS, Maurice. On collective memory. Chicago:The University of Chicago Press,1992. [em francês 1925].

${ }^{8}$ BERGER, Peter L. / Luckmann, Thomas. The social construction of reality. Nova York: Doubleday: Garden City, 1966.

${ }^{9}$ BEREK, Mathias: Kollektives Gedächtnis und die gesellschaftliche Konstruktion der Wirklichkeit. Eine Theorie der Erinnerungskulturen. Wiesbaden: Harrassowitz Verlag, 2009.

${ }^{10}$ WHITE, Hayden. Tropics of Discourse. Essays in cultural criticism. Baltimore e Londres: The John Hopkins University Press, 1978.

11 BARTLETT, Frederic. Remembering. A Study in Experimental and Social Psychology. Cambridge: Cambridge University Press, 1932, 63f-94.
} 
obstante, a forma de organização e representação da socialidade. Ao mesmo tempo, essas molduras (frames) podem se caracterizar como um modo de recordação, e este é meu argumento central.

\section{Sedimentos como recordação}

Assim, as recordações não se restringem à atualização de informações previamente armazenadas - e, aqui, tanto armazenar quanto informação devem ser entendidas como metáforas muito vagamente formuladas, já que existem noções extremamente divergentes sobre 0 ato de recordar e sobre a acessibilidade a tipos muito diferentes de informação, bem como sobre a construção de narrativas significativas e plausíveis que contêm em si a capacidade de ação e, talvez, até mesmo a de curar. Em vez disso, as recordações existem ainda de outra forma, ou seja, como as consequências práticas do passado. Desse modo, a caracterização antiga é retomada, ou seja, os acontecimentos passados conduzem a diversos tipos de experiências que governam o comportamento futuro. Tanto nas humanidades e nas ciências sociais quanto nas ciências cognitivas esse fenômeno tem sido teorizado, em termos de experiência sedimentada, por autores que utilizam uma grande variedade de conceitos. Em The Collective Memory Reader, organizado por Jeffrey K. Olick, Vered Vinitzky-Seroussi e Daniel Levi, os autores reconstituem, cronologicamente, o envolvimento com esse tema e, assim fazendo, explicitamente mapeiam uma tradição na qual se pode encontrar um bom número de conexões entre recordação e as noções de experiência sedimentada. Karl Mannheim, por exemplo, parece estar descrevendo efetivamente uma forma de disseminação inconsciente de atitudes e interpretações universais quando afirma que

Todas essas atitudes e ideias que seguem funcionando satisfatoriamente na nova situação e servem de estoque básico da vida grupal são passadas adiante e transmitidas de forma inconsciente e involuntária: elas se infiltram sem que o professor ou o aluno se deem conta do que está ocorrendo ${ }^{12}$.

Paul Connerton também se refere explicitamente a habituações, embora apenas relacionadas a aspectos performativos durante a realização de rituais de recordação. Ainda assim, ele vê a corporeidade das ações como um prérequisito para sua verdadeira aceitação pelos próprios autores, acentuando, portanto, os elementos performativos ou praxeológicos da ação:

Pois, a fim de que as cerimônias funcionem para seus participantes, para que sejam persuasivas, eles precisam ser não apenas cognitivamente competentes para executar a

12 OLICK, Jeffrey K. / Vinitzky-Seroussi, Vered / Levi, Daniel (orgs.). The Collective Memory Reader. Oxford: Oxford University Press, 2011: 96. 
performance, mas estar habituados a elas. Essa habituação é encontrada no substrato corporal da performance $\left[. . .{ }^{13}\right.$

Connerton conecta corporeidade e recordação e fala explicitamente sobre "como a memória é sedimentada, ou acumulada, no corpo". Consequentemente, ele conceitua uma "memória habitual sedimentada no corpo". ${ }^{14}$ Além disso, Olick, Vinitzky-Seroussi e Levi leem o trabalho paradigmático de sociologia do conhecimento de Peter L. Berger e Thomas Luckmann como uma contribuição para a teoria da recordação:

Berger e Luckmann fornecem uma perspectiva fenomenológica da tradição, que caracterizam como a sedimentação de experiências; esses sedimentos só podem ser transmitidos quando são materializados em sistemas de sinais, dos quais o mais comum é a linguagem ${ }^{15}$.

Jay Winter argumenta que "o dano psiquiátrico é um tipo de recordação". ${ }^{16}$ A despeito de todas as suas diferenças, esses exemplos tratam de concepções de como o passado, em forma perpetuada, permanece relevante para a ação, às vezes por meio da apropriação e internalização de práticas performativas e corporais, às vezes por meio de sistemas de sinais que ainda precisam ser identificados e, outras vezes, como um dano totalmente involuntário à ação. Isso é indicativo do amplo espectro daquilo que se quer dizer com a expressão "experiência sedimentada". E, finalmente, Maurice Halbwachs, a figura clássica dos estudos sociológicos sobre a memória, explicitamente definiu as molduras de memória como sendo também memória: "Os acontecimentos são lembranças, mas as molduras formam-se, igualmente, a partir de lembranças"17.

\section{Conceitos de experiência sedimentada nas ciências sociais e cognitivas}

Os conceitos de experiência sedimentada constituem um elo central entre recordação, entendida no sentido discutido acima, e ação, além de

${ }^{13}$ CONNERTON, Paul. How Societies Remember. Cambridge: Cambridge University Press, 1989: 338.

${ }^{14}$ CONNERTON, Paul. How Societies Remember. Cambridge: Cambridge University Press, 1989: 342.

${ }^{15}$ BERGER, Peter L. / Luckmann, Thomas. The social construction of reality. Nova York: Doubleday: Garden City, 1966: 216.

${ }^{16}$ WINTER, Jay. "From 'Remembering War: The Great War between Memory and History in the Twentieth Century"', in: OLICK, Jeffrey K. / Vinitzky-Seroussi, Vered / Levi, Daniel (orgs.). The Collective Memory Reader. Oxford: Oxford University Press, 2011: 426-430 (cit. 428)

${ }^{17}$ HALBWACHS, Maurice. On collective memory. Chicago:The University of Chicago Press, 1992. [em francês 1925], p. 144. 
descreverem as molduras socialmente estabelecidas, ou seja, os pré-requisitos da ação individual. As teorias da ação, examinadas em detalhe mais adiante, fornecem explicações sobre o que motiva a ação humana e quais os prérequisitos culturais da ação. O que uma pessoa precisa saber para conseguir agir? Ela precisa identificar situações e contextos e estar em uma posição de escolher ou de gerar e executar aquelas ações que a capacitam a lidar com as situações e os contextos identificados. Como bem sabemos a partir de nossa própria experiência, isso é muito menos difícil na prática do que parece na teoria, como se visto de fora. Por exemplo, os humanos podem usar transporte público ou comprar produtos e expressar opiniões, e assim por diante. Eles sabem como tudo funciona e têm recursos para consumar suas ações sem ter que refletir sobre elas constantemente. Isso acontece porque os atores sociais encontram-se em um mundo profundamente pré-formatado do qual se apropriaram ou, mais exatamente, do qual estão permanentemente se apropriando por meio de processos de habituação inteiramente idiossincráticos $^{18}$ ou, então, criativos $^{19}$. Assim, a ação não se baseia em decisões individuais; na realidade, ela coloca cada indivíduo em uma relação com molduras que gradualmente se transformam ao longo do tempo, isto é, com experiências sedimentadas. Essa interpretação tem sido traduzida em uma gama de conceitos que tratam exatamente dessa relação entre estrutura/moldura/cultura e o indivíduo. No entanto, em sua forma avançada essa relação não deve ser considerada como uma dualidade, mas, sim, como uma dialética.

A mais influente concepção de experiência sedimentada surgida nas últimas décadas na área das humanidades e das ciências sociais é a de habitus, desenvolvida por Pierre Bourdieu ${ }^{20}$, que se baseia, por sua vez, nos trabalhos de alguns de seus predecessores. Ela se refere à personalidade social de um indivíduo, que abrange o que é considerado como preferências culturais altamente pessoais, como as maneiras, que abrangem desde movimento até fala e opinião. De acordo com Bourdieu, todos esses aspectos estão muito menos sujeitos ao indivíduo e dependem, em muito maior medida, da posição social dentro da comunidade. No entanto, o modo como são apropriados os transforma em algo próprio do indivíduo.

Quanto a isso, a concepção de figuração de Norbert Elias é inteiramente comparável e refere-se às constelações sociais que modelam de antemão os modos de percepção e interpretação. Em particular, Elias desenvolveu as dinâmicas dessa concepção no estudo realizado com John L. Scotson em The Established and the Outsiders ${ }^{21}$. Utilizando o exemplo de uma pequena cidade inglesa, os autores comparam dois grupos e demonstram como a afiliação ao grupo que vivia há mais tempo no local ou ao daqueles chegados mais recentemente tem uma influência fundamental nos possíveis cursos de ação de

\footnotetext{
${ }^{18}$ LÜDTKE, Alf. Eigen-Sinn. Fabrikalltag, Arbeitererfahrungen und Politik vom Kaiserreich bis in den Faschismus. Hamburgo: Ergebnisse Verlag, 1993.

${ }^{19}$ JOAS, Hans. The Creativity of Action. Chicago: University of Chicago Press, 1996.

${ }^{20}$ BOURDIEU, Pierre. Outline of a Theory of Practice. Cambridge: Cambridge University Press, 1977.

${ }^{21}$ ELIAS, Norbert /Scotson, John L. The Established and the Outsiders. Londres: Frank Cass \& Co. Ltd.: 1965 (Sage 1994).
} 
seus integrantes. Elias e Scotson explicitamente identificam as experiências partilhadas como uma das causas do emolduramento do comportamento baseado em antiguidade:

O grupo das "famílias antigas" de Winston Parva (alguns de seus integrantes eram, é claro, muito jovens) tinha um passado comum; os recém-chegados não tinham nenhum. [...] Elas haviam atravessado juntas um processo de grupo - desde o passado até o presente, em direção ao futuro - que lhes fornecia um estoque comum de memórias, preferências e aversões (XXXVII-XXXVIII).

Outra concepção pertinente é a de mentalidade, particularmente predominante no campo da história. De acordo com Peter Burke, a pesquisa sobre mentalidade destaca atitudes coletivas, em vez de individuais, enfatiza suposições inconscientes, investiga a percepção de atores históricos e lida com a estrutura de opiniões, categorias e símbolos ${ }^{22}$. Ingrid Glicher-Holtey define mentalidade como "a explicação da correlação entre a disposição de agir, de um lado, e a ação social, de outro" ${ }^{\prime 23}$. Além disso, ela argumenta que a mentalidade estrutura o comportamento, mas não o determina. Em outras palavras, mentalidade é uma potencialidade ${ }^{24}$. Volker Sellin descreve mentalidade como "o modo [...] como uma coletividade interpreta uma situação". Assim sendo, envolve "um processo de decifrar a realidade e, com isso, um processo de entendimento [hermenêutico]"25. Ele conclui que mentalidade deve ser entendida no sentido de que "a ação real [...] ocorre involuntariamente, como um reflexo para o ator" ${ }^{\prime 26}$. Tomando isso em conta e levando a ideia à sua conclusão lógica, mentalidade significa, então, formas coletivas de percepção e interpretação que se tornam relevantes para a conduta social. Isso, por sua vez, leva à afirmação de Sellin de que o estudo de mentalidades deve começar com o estudo da conduta social, do comportamento real ${ }^{27}$. São evidentes as superposições das concepções de hábito e figuração, embora ambas se concentrem diretamente na apropriação individual dos modos de percepção e interpretação e em suas correspondentes pré-condições sociais.

Concepções de identidade também estão intimamente relacionadas, já que em seu núcleo reside a tarefa psicológica de engajar o self em uma relação, o que envolve promover o equilíbrio entre as próprias expectativas, atribuições e demandas e as de outros. Os já mencionados conceitos de hábito,

${ }^{22}$ BURKE, Peter, Stärken und Schwächen der Mentalitätsgeschichte. In: RAULFF, Ulrich (org.). Mentalitäten-Geschichte: Zur historischen Rekonstruktion geistiger Prozesse. Berlim: Wagenbach Verlag, pp. 127-145, 1989, p. 127.

${ }^{23}$ GILCHER-HOLTEY, Ingrid, Plädoyer für eine dynamische Mentalitätsgeschichte. Geschichte und Gesellschaft, 24, pp. 477-497, 1998, p. 477.

${ }^{24}$ GILCHER-HOLTEY, Ingrid, pp. 478-479, 484.

${ }^{25}$ SELLIN, Volker, Mentalität und Mentalitätsgeschichte. Historische Zeitschrift [HZ] 241, 1985, p. 590.

${ }^{26}$ SELLIN, Volker, Ibidem, p. 591.

${ }^{27}$ SELLIN, Volker, Op. Cit., p. 
figuração e mentalidade constituem não apenas as molduras, mas também os resultados desse processo. Assim, um hábito em fluxo constante é o resultado de um alinhamento entre emolduramento social e aspirações pessoais. No entanto, é significativo que essas aspirações já sejam, em parte, o resultado de certas constelações sociais (i.e., figurações) e também de modos coletivos específicos de percepção e interpretação (i.e., mentalidades). Assim, a identidade é, em muitos aspectos, um resultado de experiências sedimentadas ou, mais precisamente, o resultado de um processo contínuo de decifração e apropriação do mundo que circunda o indivíduo em questão.

Os scripts de vida pertencem a outra categoria de experiência sedimentada. Neste contexto, são relevantes porque, em primeiro lugar, os scripts desempenham papel indispensável nas teorias da ação. Também poderiam ser traduzidos como automatismos ou rotinas, já que, de fato, referem-se à pré-formação dos cursos de ação específicos de uma situaçã̃o ${ }^{28} \mathrm{e}$ não requerem nenhum tipo de decisão deliberada da parte dos atores. Assim, de acordo com Hartmut Esser, "molduras e scripts são modelos mentais de situações e sequências de ações típicas que são armazenados na memória, ligados a conteúdos específicos e centrados em certos aspectos, e simplificam a 'realidade' drasticamente" ${ }^{\prime 29}$. Em segundo lugar, o conceito de scripts deriva da pesquisa da memória nas ciências cognitivas e faz a ligação entre conceitos de molduras e ação. Essa teoria foi desenvolvida no contexto da memória autobiográfica que pode, de fato, ser entendida como uma conciliação entre o que é visto como marcos culturalmente significantes, mas totalmente estereotipados, e uma vida vivida com sua experiência individual ${ }^{30}$ : "[...] o script de vida é transmitido por gerações antigas, histórias e observações do comportamento de outras pessoas (tipicamente, de pessoas mais velhas) dentro da mesma cultura" ${ }^{\prime 31}$. No processo, também são transmitidas indicações sobre quando, em que idade (normas etárias), em que estágios do desenvolvimento (transformações de papéis) devem ocorrer idealmente (ibid.) Presume-se que esse tipo de emolduramento funcione em duas direções: retrospectivamente, em termos da construção de uma história de vida na qual se supõe que a experiência individual desempenhe uma função moderadora, especialmente nas sociedades ocidentais ${ }^{32}$, e prospectivamente, atuando os scripts como narrativas ancoradas em práticas sociais e em instituições com origens diversas e de caráter obrigatório, como escola, casamento ou parceria. Tal como nas concepções de experiência sedimentada discutidas anteriormente, aqui também é evidente a íntima conexão entre estrutura e apropriação. Práticas mudadas alteram os modos da narrativa e o conteúdo significante de

\footnotetext{
${ }^{28}$ KRONEBERG, Clemens. Die Erklärung sozialen Handelns. Grundlagen und Anwendung einer integrativen Theorie. Wiesbaden: VS Verlag, 2011; 121-122; STRAUSS, Anselm. Continual Permutations of Action. New York: Aldine de Gruyter, 1993: 193.

${ }^{29}$ ESSER, Hartmut. Soziologie. Spezielle Grundlagen. Band 6: Sinn und Kultur. Frankfurt am Main/Nova York: Campus, 2001, p. 262.

30 BERNTSEN, Dorthe / Rubin, David. C. Cultural life scripts structure recall from autobiographical memory. Memory \& Cognition, 32 (3), pp. 427-442, 2004.

${ }^{31}$ BERNTSEN, Dorthe Rubin, David. p. 429.

32 GLÜCK, Judith / Bluck, Susan. Looking back across the life span: A life story account of the reminiscence bump, Memory \& Cognition, 35 (8), pp. 1928-1939, 2007.
} 
instituições, e vice-versa. Os scripts de vida emolduram ações na medida em que estejam assentados sobre uma base cultural (por exemplo, por meio de narrativas e instituições) e cognitiva (por exemplo, em formas de percepção e interpretação que poderiam estar registradas na estrutura do script).

Modelos mentais, também chamados modelos situacionais, relacionamse com as molduras cognitivas, mas são constituídos por meio de experiências pessoais, tenham elas a forma de conhecimento episódico ou tenham natureza mais implícita, como opiniões, atitudes ou conhecimento sobre a estrutura e o conteúdo de relações sociais ${ }^{33}$. Eles modelam, de antemão, percepções futuras, mas "não são inteiramente pessoais. Também têm importantes dimensões sociais, intersubjetivas. Devido a interações e comunicações anteriores, e, o que é mais comum, devido à sua socialização, os usuários da linguagem adquiriram vários tipos de conhecimento e crenças sociais partilhados ${ }^{\prime \prime 34}$. Tendo essas ideias como ponto de partida, e levando em conta a comunicação (verbal), Teun van Dijk esboça uma teoria dos chamados modelos de contexto:

São subjetivos, representam experiências pessoais, ou seja, a experiência do episódio comunicativo corrente, e também exibem representações mentais de conhecimento sociocultural que partilhamos a respeito de situações sociais e comunicativas e daqueles que delas participam ${ }^{35}$.

Esses modelos, baseados na experiência individual e coletiva, capacitam os indivíduos a agir adequadamente, i.e., a corresponder às expectativas de quase todos os envolvidos em uma situação comunicativa e, assim, a lidar com essa situação de acordo com os conceitos da teoria da ação. Desse modo, independentemente da moldura socialmente mediada, suas ações são de natureza individual.

Finalmente, mas, de forma alguma, em termos conclusivos, as instituições são as mais tangíveis e, empiricamente, as mais mensuráveis expressões de experiências históricas, qualquer que seja seu formato: por exemplo, instituições investidas de tarefas, regulações e recursos específicos, como a polícia ou o judiciário; constructos legais, como os Direitos Humanos Universais; ou formas codificadas de interação social, como o casamento. Numa outra tradução das perspectivas contidas na sociologia do conhecimento sobre as teorias da memória, Dariuš Zifonun oferece uma compreensão menos formalizada de instituições. De forma bastante semelhante à de Peter L. Berger e Thomas Luckmann, ele discute um processo de consolidação de atividades inicialmente isoladas que, em decorrência da repetição, conduzem, primeiro, à sua habituação e, finalmente, à institucionalização, especialmente quando esses

\footnotetext{
33 JOHNSON-LAIRD, Philip Nicholas. Mental Models: Towards a Cognitive Science of Language, Inference and Consciousness. Cambridge: Harvard University Press, 1983.

${ }^{34}$ VAN DIJK, Teun A. Society and Discourse. How Social Contexts Influence Text and Talk. Cambridge: Cambridge University Press, 2009.

${ }^{35}$ VAN DIJK, Teun, ibid. Pp. 6-7.
} 
modelos de ação são adotados por outros ${ }^{36}$. De acordo com essa interpretação, instituições são produtos de práticas e experiências, independentemente de como sejam compostas. No entanto, deve-se agregar que a ação com a qual se inicia essa sequência altamente idealizada é, em si mesma, mediada e emoldurada de formas muito diversas. Apesar disso - e aí está o momento dialético -, pode ocorrer até mesmo uma apropriação inteiramente original dessa estrutura em face de uma situação específica. No entanto, Zifonun não vê como memórias essas instituições que evoluíram ao longo da história, nem mesmo ao falar sobre a institucionalização de memórias, quando ocorre um acordo intersubjetivo a respeito da interpretação do passado. Ainda assim, continuou sem exame o fato de que as molduras de tais processos são, elas mesmas, fortemente determinadas pelo passado. A esse respeito, fica minimizado o caráter construtivo das memórias, sempre tão enfatizado - e não apenas por Zifonun. Esse ponto torna-se ainda mais relevante quando se considera que as recordações são muito mais do que aquilo que contêm, mais do que as histórias ou as interpretações que englobam; não apenas são transmitidas, passadas adiante $e$, assim, instaladas como partes de uma memória, mas também são, de forma evidente e muito mais fundamental, estruturas narrativas e os sempre cambiantes contextos de sua utilização ${ }^{37}$.

Em suma, e de acordo com inúmeras conceituações teóricas das quais apenas algumas foram vistas aqui, pode-se dizer que experiências sedimentadas são resultados do passado que têm relevância para 0 comportamento social; elas emolduram até mesmo os processos de recordação. Na maior parte das vezes, e especialmente durante a ação, elas estão apenas marginalmente disponíveis para a consciência e, portanto, apenas sob relativo controle do ator social. Em contraste, existem aquelas construções narrativas do passado, de natureza ideal-típica, cujo propósito é moldar histórias sobre a entidade representada (pessoa, grupo, instituição); elas ajudam a gerar coerência, orientação, significado e coisas semelhantes. Ao lado disso, existe também, como se poderá ver em um rápido exame dos livros-textos de pesquisas sobre memória, uma série de outros tipos de memória igualmente relevantes para a ação e que também resultam de experiências anteriores. Exemplos disso são a ativação prévia (priming) - "que significa uma maior probabilidade de reconhecimento de um estímulo previamente recebido de forma igual ou semelhante" ${ }^{\prime 38}$ - e as memórias processuais (procedural memories) e perceptivas, não inteiramente compostas de narrativas. No futuro, esses esquemas devem ser suplementados com as experiências sedimentadas de segunda ordem, tal como descritas neste texto. Finalmente, ainda precisamos acrescentar as experiências sedimentadas de primeira ordem. Na

\footnotetext{
36 ZIFONUN, Dariuš. "Vergessende Erinnerung": Eine Wissenssoziologie des Erinnerns und Vergessens. In: Oliver Dimbath, Peter Wehlling (orgs.). Soziologie des Vergessens. Theoretische Zugänge und empirische Forschungsfelder. Konstanz: UVK Verlagsgesellschaft, 2011, p. 195.

${ }^{37}$ GUDEHUS, Christian. Tradierungsforschung. In: Christian Gudehus, Ariane Eichenberg, Harald Welzer (orgs.). Gedächtnis und Erinnerung. Ein interdisziplinäres Handbuch. Stuttgart: J.B. Metzler, pp. 312-318, 2010.

${ }^{38}$ PIEFKE, Martina / Markowitsch, Hans J. Neuroanatomisch und neurofunktionelle Grundlagen von Gedächtnis. In: Christian Gudehus, Ariane Eichenberg, Harald Welzer (orgs.). Gedächtnis und Erinnerung. Ein interdisziplinäres Handbuch. Stuttgart: J.B. Metzler, pp. 11-21, 2010.
} 
falta de um conceito adequado, elas são discutidas aqui como os componentes desencadeados (triggered) do conhecimento.

\section{Componentes desencadeados do conhecimento}

Num programa sobre ciências na televisão inglesa, chamado Bang Goes the Theory, foi apresentado o seguinte experimento (youtube: http://www.youtube.com/watch?v=5fLomC5LGa) ${ }^{39}$. Pediu-se a um grupo disposto a participar de alguns experimentos que contasse pedaços de papel com uma mão, e a outro grupo que contasse dinheiro da mesma forma. Em seguida, foram apresentadas as tarefas que faziam parte do experimento propriamente dito. Na primeira delas, algumas travessas com doces foram colocadas sobre a mesa, e os participantes deveriam julgar a qualidade de cada doce. Aqueles que haviam contado tiras de papel comeram somente os doces necessários para poder responder a uma lista de perguntas, enquanto os que haviam contado dinheiro comeram, em média, cinquenta por cento a mais. A suposta conexão é que o dinheiro está associado a recursos, e esses, por sua vez, a alimento ("ligados pelo mesmo impulso básico de sobreviver"). Além disso, a referência a dinheiro e riqueza (como uma conexão positiva) foi reforçada enquanto o grupo que havia contado dinheiro estava recebendo sua tarefa, mas o grupo de controle recebeu a mesma tarefa sem ouvir nenhuma referência sugestiva. Depois disso, câmaras ocultas observaram 0 comportamento dos participantes em algumas situações. Numa delas, uma mulher previamente instruída para isso deixava cair seus documentos. Apenas alguns dos indivíduos previamente ativados pela contagem de dinheiro a ajudaram, em comparação com os integrantes do outro grupo. A explicação proposta foi que o dinheiro torna uma pessoa mais autoconfiante, e quem se percebe assim frequentemente espera que o mesmo ocorra com os demais e, portanto, não presume que sua ajuda seja desejada ou necessária. No experimento final mostrado no filme, pediu-se aos participantes que mantivessem suas mãos mergulhadas em água gelada pelo maior tempo que conseguissem. Na média, aqueles do grupo do dinheiro resistiram o dobro do tempo. Provavelmente, conseguiram isso porque dinheiro está associado a poder, e poder está associado a força física. O que claramente influenciou o comportamento dos atores nessa situação foram componentes de conhecimento que não haviam sido verbalizados, explicitados ou invocados como tal. Neste caso, eles não podem ser descritos em termos mais precisos, já que não eram crenças nem atitudes. As associações propostas (dinheiro = recursos, independência, poder) mudaram as inclinações situacionais dos atores de tal forma que, na média (i.e., nem todos exatamente do mesmo modo), eles

\footnotetext{
${ }^{39}$ Aqui, a base do argumento é, entre outros, o estudo de Vohs, Mead e Good (2006).
} 
agiram de forma significativamente diferente daqueles que não foram submetidos aos mesmos elementos desencadeadores ${ }^{40}$.

Mas tais investigações envolvem diversos problemas. O mais importante (e que constitui a crítica mais bem fundamentada ao estudo) refere-se ao fato de que, não intencionalmente, as expectativas dos que conduzem os experimentos são comunicadas aos participantes e, assim, influenciam seus comportamentos $^{41}$. Consequentemente, os resultados de centenas de estudos sobre o efeito da ativação prévia são provisórios por natureza. No entanto, parece prematuro considerá-los todos falsos. Assim, não se pode negar que existe base suficiente para se assumir a existência de conceitos mentais que podem ser reforçados e que, por sua vez, influenciam o comportamento. Como no caso presente, esses conceitos são modos coletivos de interpretação que, com frequência, são culturalmente ancorados e transportados e, por isso, contêm um efeito do passado que é relevante para a ação. Mas, mesmo naqueles experimentos nos quais a mudança no comportamento não foi causada por uma ativação prévia, sendo um resultado das expectativas involuntariamente comunicadas dos que dirigiam o experimento, ainda é possível falar de um efeito secundário do passado que é relevante para o comportamento, de vez que a consciência dessa intenção supostamente bem ocultada está fortemente carregada com seus próprios pré-requisitos.

Em seu trabalho sobre a existência, ou não, de uma base biológica para o julgamento moral, Marc D. Hauser apresenta vários estudos sobre desencadeadores que manipulam o comportamento; em seguida, ele identifica as causas históricas (culturais) desses desencadeadores. Para isso, examina detalhadamente o estudo no qual Richard E. Nisbett e Dov Cohen provam, em diversos ambientes experimentais, que, quando maltratadas e insultadas (com termos ofensivos como "idiota"), as pessoas do sul dos Estados Unidos claramente reagiam de forma mais agressiva do que as originárias do norte ${ }^{42}$. A fim de explicar essa constatação, eles recorrem ao passado e argumentam que, no sul, desenvolveu-se uma "cultura de honra" que pode ser entendida, em essência, como uma resposta à prática de criação de gado e ao fato de o roubo de gado ser um grave problema em um mundo pouco regulado por instituições formais. Nisbett e Cohen

acreditam que sociedades pastoris têm culturas de honra por razões associadas à precariedade econômica dos criadores, que constantemente enfrentam a possibilidade de perder toda a sua riqueza - caso percam seus rebanhos. Assim, uma postura agressiva e à disposição de matar ou criar tumulto servem para

\footnotetext{
${ }^{40}$ Seria interessante repetir os experimentos com participantes que têm uma atitude negativa com relação ao dinheiro. Caso não ajam de forma significativamente diferente, isso provaria o efeito do inconsciente (na linguagem psicanalítica) ou do que chamo de motivadores de ação "não disponíveis", que contradizem as crenças e até os sentimentos desses indivíduos.

${ }^{41}$ DOYEN S, Klein O, Pichon C-L, Cleeremans A. Behavioral Priming: It's All in the Mind, but Whose Mind? (2012) Behavioral Priming: It's All in the Mind, but Whose Mind? PLoS ONE 7(1): e29081. doi:10.1371/journal.pone.0029081

${ }^{42}$ NISBET, Richard E. / Cohen, Dov. Culture of Honor: The Psychology of Violence in the South. Boulder: Westview Press, 1996.
} 
anunciar a determinação de proteger seus animais a todo custo $^{43}$.

Hauser resume esse processo nos seguintes termos: "As culturas de honra [...] têm um ponto de origem comum. Elas se desenvolvem em situações nas quais os indivíduos têm de aplicar a lei com as próprias mãos porque não existe nenhuma lei formal que os proteja daqueles que podem roubar seus recursos valiosos" ${ }^{\prime 4}$. Já vimos acima, com referência a Berger e Luckmann, a questão de como, por meio de atividades perpetuamente repetidas, desenvolvem-se instituições no sentido mais amplo (e também culturas que emolduram percepções e interpretações, mais exatamente descritas como mentalidades). Nesse contexto, é notável que a análise de Nisbett e Cohen mostre "como a psicologia que sustenta a norma social pode resistir a mudanças até muito tempo depois de o desencadeador ou catalisador original haver desaparecido"${ }^{45}$.

Outro tipo de experiência, de natureza avulsa ou não conectada, que não é traduzida como uma narrativa tem sido discutido no contexto de tratamentos médico-psicológicos após experiências graves, negativas. Günter H. Seidler define as chamadas intrusões neste contexto da seguinte forma:

Intrusões (lat. Intrūděre: penetrar) são fragmentos de memória relacionados a eventos potencialmente letais. A partir de um desencadeador, i.e., de um estímulo semelhante, esses fragmentos se infiltram na experiência das pessoas afetadas. As intrusões não são experiências em nenhum sentido real, mas novas versões da situação experimentada no passado. Durante o armazenamento das percepções sensoriais naquela ocasião, as funções contextualizadoras de determinada estrutura cerebral, ou seja, do hipocampo, são temporariamente desligadas, provavelmente sob o efeito do cortisol, o hormônio do estresse. Assim, essas percepções não são integradas na memória autobiográfica, o que significa não serem contextualizadas e, em termos figurativos, não possuírem coordenadas de espaço e tempo ${ }^{46}$.

O desconhecimento de que se trata, de fato, de uma memória que pode ser reativada poderia ser compreendido como característica dessa forma de recordação, ou seja, de uma experiência sedimentada. Em termos de uma diferenciação ainda preliminar, podem ser distinguidos dois tipos de experiências: as de segunda ordem constroem as molduras da percepção,

\footnotetext{
${ }^{43}$ NISBET, Richard E. / Cohen, Dov., ibidem, 1996: 5.

${ }^{44}$ HAUSER, Marc D. Moral Minds. How nature designed our universal sense of right and wrong.: Londres: Abacus, 2006: 145.

${ }^{45}$ NISBET, Richard E. / Cohen, Dov. Culture of Honor: The Psychology of Violence in the South. Boulder: Westview Press, 1996: 148.

${ }^{46}$ SEIDLER, Günter H. Gewaltfolgen - Individuell. In: Christian Gudehus, Michaela Christ (orgs.). Gewalt. Ein interdisziplinäres Handbuch. Stuttgart: J.B.Metzler, pp. 243-250, 2013: 245.
} 
interpretação e ação, enquanto as de primeira ordem podem ser desencadeadas e, involuntariamente, deflagrar comportamentos. Alternativamente, e talvez de modo mais convincente, todas as formas e concepções de experiência sedimentada mencionadas até agora, que diferem marcadamente umas das outras em muitos aspectos, poderiam ser descritas como diferindo apenas parcialmente em dois aspectos: primeiro, em termos da possibilidade de torná-las conscientes ou disponíveis e, portanto, de serem parte da decisão conscientemente deliberada de agir; e, segundo, intimamente ligado ao primeiro, em termos do grau em que afetam ações específicas. A discussão sobre esses dois temas - a relevância mediada ou não mediada para a ação, e a racionalidade fundamental ou o determinismo da ação humana nos conduz diretamente à seção final, ou seja, à discussão da relação entre experiência e algumas das concepções importantes da teoria da ação.

\section{De "automatizada" a "deliberada"}

As teorias da ação também se preocupam com essa diferença obviamente fundamental entre automatismo e deliberação. Até abordagens que parecem basicamente diferentes convergem para a ideia de que existem modos automatizados, rotinizados, talvez isentos de qualquer deliberação, para avaliar situações e delas se apropriar ou desenvolver uma ação (de acordo com uma perspectiva da teoria social, Joas $1996^{47}$ ) ou para fazer uma escolha (de acordo com a abordagem da escolha racional, Kroneberg $2011^{48}$ ). Em contraste, há aqueles que consideram necessário um alto nível de confrontação consciente, reflexiva (e, no sentido empatético da palavra, considerada) com a situação de ação a fim de fazer justiça às exigências que se combinam de diferentes formas em todas as situações. Hartmut Esser sistematizou os pontos de acordo entre as teorias da escolha racional e a teoria social de Alfred Schütz. O que mais interessa a essas duas abordagens são as diferenciações entre modos rotinizados, baseados na habituação, e aqueles precedidos por uma deliberada "escolha entre projetos de ação, como faz um contabilista" 49 .

Clemens Kroneberg, um aluno de Esser, faz uma distinção comparável e distingue entre um modo reflexivo-calculado de processamento de informação dentro do marco de referência de processos de ação e um modo automáticoespontâne $\sigma^{50}$. Insights comparáveis também podem ser encontrados nos escritos de Hans Joas, embora formulados de modo bastante diferente:

\footnotetext{
${ }^{47}$ JOAS, Hans. The Creativity of Action. Chicago: University of Chicago Press, 1996.

${ }^{48}$ KRONEBERG, Clemens. Die Erklärung sozialen Handelns. Grundlagen und Anwendung einer integrativen Theorie. Wiesbaden: VS Verlag, 2011.

${ }^{49}$ ESSER, Hartmut. The Rationality of Everyday Behavior: A Rational Choice Reconstruction of the Theory of Action by Alfred Schütz. Rationality and Society, 5: 7, 1993 [DOI: $10.1177 / 1043463193005001003]$

${ }^{50}$ KRONEBERG, Clemens. Die Erklärung sozialen Handelns. Grundlagen und Anwendung einer integrativen Theorie. Wiesbaden: VS Verlag, 2011: 145.
} 
Dado que as formas fundamentais de nossa capacidade para a ação residem no movimento intencional de nosso corpo em conexão com a locomoção, a manipulação do objeto e a comunicação, nosso mundo é inicialmente estruturado de acordo com essas dimensões. Dividimos o mundo em categorias - acessível e inacessível, familiar e não familiar, controlável e incontrolável, responsivo e não responsivo. Se essas expectativas relacionadas com a ação, inerentes à nossa percepção do mundo, não são satisfeitas, nós de fato nos dissociamos de uma parte do mundo que agora, surpreendentemente, se revela inacessível e não familiar, incontrolável ou não responsiva, e atribuímos a ela o status de um objeto externo ${ }^{51}$.

"Isso significa", argumenta Joas, "que até os fatos da mais extrema criatividade presumem a pré-existência de um fundamento subjacente de ações rotineiras e condições externas que são simplesmente tomadas como um dado $^{\prime 52}$. Até agora, as palavras agir e comportar-se não foram definidas e são usadas como sinônimos. Se alguém fosse fazer essa diferenciação em termos de interpretações culturais-psicológicas, como fizeram Heinz-Jürgen Kaiser e Hans Werbik com referência a Norbert Groeben, seria possível distinguir entre comportar-se, fazer e agir. Portanto, as ações representam somente "aquelas formas de comportamento pelas quais os seres humanos poderiam ser responsabilizáveis, aquelas que alguém decidiu realizar" ${ }^{\prime \prime 3}$. Se comportar-se abrange "a menos deliberada, consciente e complexa arte de formas humanas de comportamento", fazer, em contraste, é o resultado das decisões de uma pessoa - que, no entanto, não pode acessar seus próprios motivos ou razões ${ }^{54}$. Neste contexto, também seria possível diferenciar de acordo com o grau de intencionalidade e a disponibilidade a ela associada, e, portanto, de acordo com a possibilidade de refletir sobre uma decisão pessoal. As diferenças entre as várias abordagens não devem, de forma alguma, ser negadas, mas, ainda assim, é notável a convergência entre diferentes modos de tomar decisões, e isso, em última instância, articula a relação entre elementos reflexivos e automatizados em qualquer teoria da ação. Para concluir brevemente, automatismos, rotinas, scripts, molduras etc. têm, conceitualmente, uma íntima relação com as concepções de experiência sedimentada. Assim sendo, não apenas é impossível compreender a recordação sem considerar sua significância para a ação humana, mas também não se pode teorizar adequadamente as ações sem expandir o conceito de recordação, agregandoIhe $\mathrm{o}$ de experiências sedimentadas.

\footnotetext{
${ }^{51}$ JOAS, Hans. The Creativity of Action. Chicago: University of Chicago Press, 1996, pp. 158-9.

52 JOAS, Hans, ibiden, p. 197.

${ }^{53}$ KAISER, Hans Jürgen; Werbik, Hans. Handlungspsychologie. Eine Einführung. Göttingen: Vandenhoek \& Ruprecht, 2012: 41.

${ }^{54}$ KAISER, Hans Jürgen; Werbik, Hans. Ibidem, pp. 41-42
} 
Com relação ao título do livro, i.e. Theorizing Social Memories: Concepts and Contexts, pode-se verificar que as experiências sedimentadas, como resultado de interações entre seres humanos, instituições e o mundo físico, precisam ser vistas como memórias sociais per se em pelo menos dois aspectos: além de modelar, de antemão, a percepção e interpretação do mundo social e físico, também constituem, com isso, os tão frequentemente invocados pré-requisitos sociais de todas as formas de apropriação do mundo.

\section{Sobre o autor}

Christian Gudehus atua no Kilian-Köhler-Centrum für sozial- und kulturwissenschaftliche Psychologie und historische Anthropologie, Ruhr-UniversitätBochum. E-mail: Christian.Gudehus@rub.de.

Artigo recebido em 10 de maio de 2014. Aprovado em 27 de junho de 2014. 